\title{
Effect of Homogenization Treatment on Microstructure and Property of Al-B Electrician Round Rod
}

\author{
Ting-yi Lin ${ }^{a}$, Xiao-yan Zhang ${ }^{\text {b, }}$, Xin Huang , Xiang-peng Gong and \\ Jun-jie Zhang \\ (School of Materials and Metallurgy, Guizhou University, Guiyang 550025, China) \\ ${ }^{a}$ lintingyi2010@163.com, ${ }^{\text {b. }}$ corresponding author:ivzhangxiaoyan@163.com
}

Keywords: Al electrician round rod, homogenization, electrical conductivity, tensile strength

\begin{abstract}
The effects of homogenization treatment on the electrical conductivity, tensile strength and microstructure of Al-B electrician round rod were investigated by means of tensile test, optical microscopy(OM), scanning electron microscopy (SEM), energy dispersive spectroscopy(EDS). The results indicate that during homogenization the grain boundary of samples became thinner, microstructure was more compact and well-distributed. As-cast Al electrician round rod has favorable comprehensive properties under homogenization at $430^{\circ} \mathrm{C}$ for $3 \mathrm{~h}$, the electrical conductivity and tensile strength reach to $58.1 \% \mathrm{IACS}$ and $100 \mathrm{MPa}$, respectively. Compared to the sample without homogenization, the electrical conductivity increased by $2.1 \%$ IACS in the case of tensile strength was not reduced. After $83 \%$ rolling processing of specimen with better comprehensive performance, the electrical conductivity and tensile strength of samples reach to $55.24 \% \mathrm{IACS}$ and $209 \mathrm{MPa}$, respectively.
\end{abstract}

\section{Introduction}

Aluminum and its alloy are widely applied in the wire and cable industry due to its excellent properties,such as good electrical conductivity, low density, high specific strength and corrosion resistance [1,2]. Since electrical round aluminum rods are used as the blank of cables and wires, the electrical conductivity and mechanical properties of electrical round aluminum rod directly influences the merits of the aluminum wire [3]. Nowadays, with the rapid development of power industry, especially in the large span transmission line, there are higher demands for the property of electrical round aluminum rods, however, original aluminum wires used for transmission can not meet the needs of large load transmission capacity, long distance and large capacity, which leads to the research of new materials with large span transmission line becoming more and more urgent $[4,5]$. Research shows that certain degree of homogenization can obtain uniform structure, eliminate dendritic segregation and reduce internal stress of aluminum alloy, thus acquiring Al electrician round rod with better comprehensive performance $[6,7,8,9]$. In this paper, based on the Al-B electrician round rod, the effects of homogenization treatment on the electrical conductivity, tensile strength and microstructure of Al-B electrician round rod are studied.

\section{Experimental}

\subsection{Experimental processing technology}

The materials in the experiment include aluminum ingot $(0.02 \%$ boronizing filter $)$, intermediate alloy Al-Y, Al-Ce, Al-La and Al-Cu. Preparing master alloy is the first step of experiment, then, putting aluminum raw materials into the crucible, adding intermediate alloy to the crucible after melting, and stir evenly. Finally, casting into cylindrical specimens with the size of $\Phi 11 \mathrm{~mm} x$ $120 \mathrm{~mm}$. Rolling processing of $83 \%$ deformation was conducted on specimen with better comprehensive performance after homogenization treatment.

\subsection{Analysis and test methods}

QJ57 arms bridge was conducted to analyze the electrical conductivity of specimen; Rolling 
process was performed by the F50-150 type rolling round machine at room temperature; Instron-8501 materials tensile tester with the stretching rate of $2 \mathrm{~mm} / \mathrm{min}$ was used to test the tensile strength of the sample. Microstructure and element distribution of the sample were observed by Olympus-BH2 optical microscope(OM), SUPRA40 field emission scanning electron microscope(SEM) and APOLLO-10Xspectrometer.

\section{Results and discussion}

\subsection{Effect of different homogenization on electrical conductivity and tensile strength}

The effect of different homogenization treatment on the properties of the sample is shown in figure 1. As shown in Fig.1(a), whether specimens were under giving temperature or time, with the increase of homogenization temperature or time, electrical conductivity of samples increased first, and then decreased. The electrical conductivity of sample reached to larger value (58.1\% IACS) after homogenization at $430^{\circ} \mathrm{C}$ for $3 \mathrm{~h}$, this is mainly because there were more second phase particles precipitated from the matrix at $430^{\circ} \mathrm{C}$ for $3 \mathrm{~h}$, which weakened the scattering effect of electrons from lattice distortion, caused by the atoms dissolved in the $\mathrm{Al}$ matrix , thus lowering the resistivity and improving the electrical conductivity of samples.
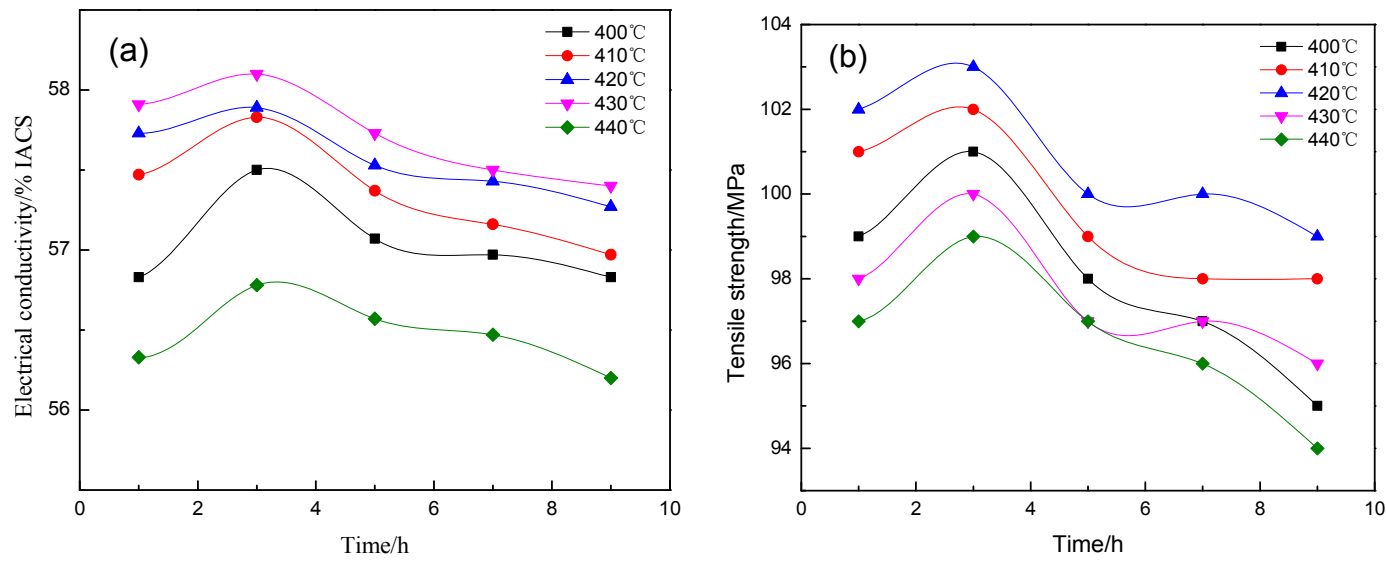

Fig.1 Effect of different homogenization treatment on property of sample:

(a)electrical conductivity, (b)tensile strength

The effect of homogenization on the tensile strength of studied alloy is shown Fig.1(b). As shown in Fig.1(b), at giving time, with the increase of homogenization temperature, the tensile strength of specimens increased at beginning and then decreased. Moreover, tensile strength of samples reached to peak value $(103 \mathrm{MPa})$ during homogenization for $3 \mathrm{~h}$ at $420^{\circ} \mathrm{C}$. This may be because after homogenization treatment at $420^{\circ} \mathrm{C}$ for $3 \mathrm{~h}$, it could eliminate the most part of dendritic segregation, uniform microstructure, reduce internal stress and refine second phase particles precipitated in the matrix, which enhanced the tensile strength of samples. But the tensile strength of the alloy continuously decreased with increasing of homogenization temperature and time.This is perhaps due to second phase particles gathering and coarsening at higher temperature, which can be the crack source of alloy to some extent and weaken the effect of Al matrix, reducing the strength of sample.

In conclusion, the optimal homogenization treatment processing is holding at $430^{\circ} \mathrm{C}$ for $3 \mathrm{~h}$, the electrical conductivity and tensile strength reach to $58.1 \%$ IACS and $100 \mathrm{MPa}$, respectively. Compared to the sample without homogenization, the electrical conductivity increased by $2.1 \%$ IACS in the case of tensile strength was not reduced. After $83 \%$ rolling processing of specimen with better comprehensive performance, the electrical conductivity and tensile strength of samples reach to $55.24 \% \mathrm{IACS}$ and $209 \mathrm{MPa}$, respectively.

\subsection{Optical microstructure at different homogenization processings}

The typical optical microstructure of as-cast and different homogenization treatment alloys are shown in Fig.2. It can be seen from Fig. 2 that the grain size of as-cast alloy was thick and that of the 
samples after homogenization treatment were finer, especially sample homogenized at $420^{\circ} \mathrm{C}$ for $3 \mathrm{~h}$, showing the microstructure of the alloy was uniformed obviously during homogenization treatment(Fig.2(c)), and the tensile strength of sample was about to $103 \mathrm{MPa}$. This is mainly because specimen during homogenization, dendritic segregation was eliminated, microstructure was uniformed, internal stress was reduced and second phase particles precipitated in the matrix was refined, thus improving the tensile strength of samples. The OM image of sample(during homogenization at $430^{\circ} \mathrm{C}$ for $3 \mathrm{~h}$ ) with $83 \%$ rolling deformation is shown in Fig.2(e). It can be noted from Fig.2(e) that in the process of rolling, the grain size of sample was obviously refined, the grain boundary was thinned, the structure was more compact, and a small amount of second phase disposed in the grain boundary originally distributed in matrix evenly and dispersively. It can be seen that the grain of sample was broken and the grain boundaries became blurred after rolling treatment. The electrical conductivity of sample was fallen slightly, but tensile strength improved significantly, the electrical conductivity and tensile strength reached to $55.24 \% \mathrm{IACS}$ and $209 \mathrm{MPa}$, respectively.

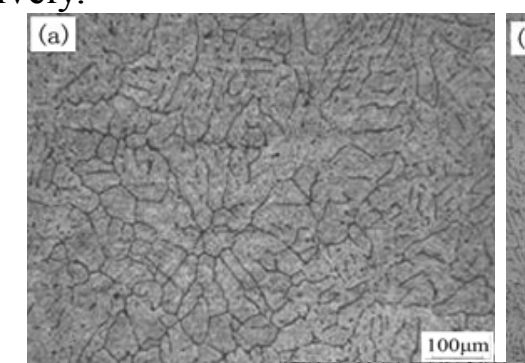

(d)

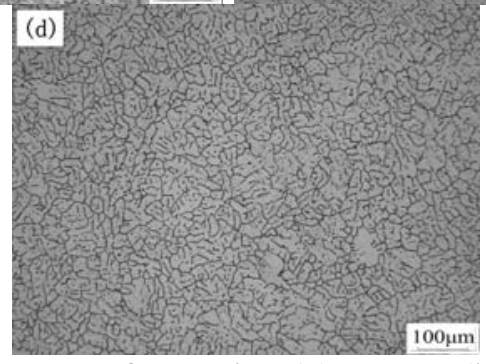

Fig. 2 Microstructure of samples:(a)as-cast,(b) $410^{\circ} \mathrm{C} \times 3 \mathrm{~h},(\mathrm{c}) 420^{\circ} \mathrm{C} \times 3 \mathrm{~h},(\mathrm{~d}) 430^{\circ} \mathrm{C} \times 3 \mathrm{~h}$,

(e) $83 \%$ rolling treatment
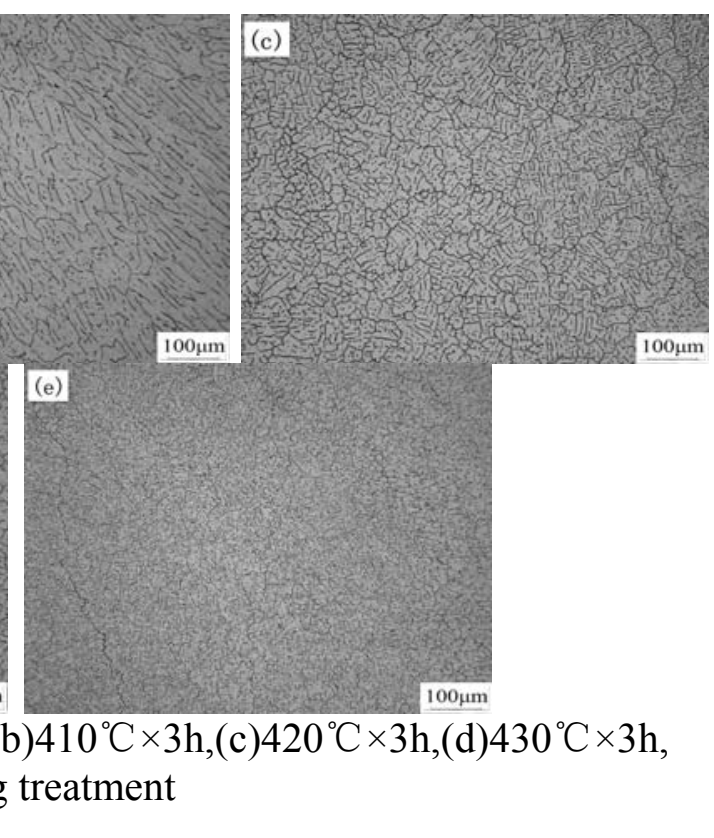

\subsection{SEM and EDS analysis}

The SEM images under different multiples of sample during homogenization at $430^{\circ} \mathrm{C}$ for $3 \mathrm{~h}$ is shown in Fig.3. It can be known from Fig.3 that the microstructure of sample was mainly composed of grain boundary, the aluminum substrate and phases precipitated from Al substrate, and compounds precipitated both in the grains and grain boundary. The EDS analysis results of the strip and particle phases in the Fig.3(c) were shown in table 1, it can be found that there were $\mathrm{Cu}, \mathrm{La}, \mathrm{Ce}$ and Y elements mainly concentrated in the grain boundary. Some elements were transformed from the state of solid solution into precipitation, which can improve the regularity of the ion electric field, leading to the increase of conductivity $[10,11]$. Moreover, the second phase dispersed on the substrate could improve the tensile strength of samples, showing the better comprehensive performance both electrical conductivity and tensile strength [12].
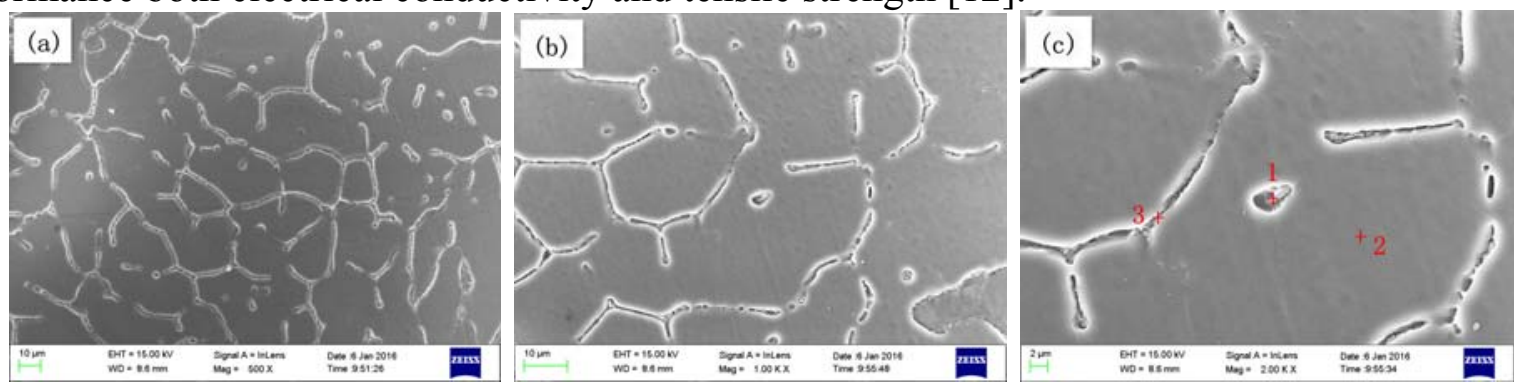

Fig.3 SEM images of sample under $430^{\circ} \mathrm{C} \times 3 \mathrm{~h}$ homogenization treatment: (a) $\times 500$, (b) 1000 , (c) $\times 2000$ 
Table 1 EDS analysis result of sample $/ \%$

\begin{tabular}{ccccccc}
\hline \multicolumn{2}{c}{ Elements } & $\mathrm{Al}$ & $\mathrm{Cu}$ & $\mathrm{La}$ & $\mathrm{Ce}$ & $\mathrm{Y}$ \\
\hline \multirow{3}{*}{$\mathrm{Wt} \%$} & 1 & 89.79 & 5.87 & 2.05 & 1.92 & 0.38 \\
& 2 & 98.34 & 0.93 & 0.47 & 0.26 & - \\
& 3 & 86.27 & 6.67 & 3.91 & 2.66 & 0.49 \\
\hline
\end{tabular}

\section{Summary}

(1) During homogenization treatment, the grain refinement effect of Al-B electrician round rod is obvious, the microstructure of samples is relatively uniform, and the grain boundary is more pure. Besides, the content of interdendritic substance decrease significantly, and the second phases are diffusely distributed in the matrix.

(2) During homogenization at $430{ }^{\circ} \mathrm{C}$ for $3 \mathrm{~h}$, the comprehensive performance of sample is relatively good, of which electrical conductivity and tensile strength reach to $58.1 \% \mathrm{IACS}$ and $100 \mathrm{MPa}$, respectively. Compared to the sample without homogenization, the electrical conductivity increased by $2.1 \% \mathrm{IACS}$ in the case of tensile strength is not reduced.

(3) After $83 \%$ rolling processing of specimen with better comprehensive performance, the electrical conductivity of sample decreases slightly, but tensile strength improves significantly, the electrical conductivity and tensile strength arrive to $55.24 \% \mathrm{IACS}$ and $209 \mathrm{MPa}$, respectively.

\section{Acknowledgments}

This work was financially supported by Science and Technology Plan Projects in Guizhou Province(No.2012-3043).

\section{Corresponding author}

Xiao-yan Zhang(1960-), female, Professor. Research Interests: The investment and application of new materials; E-mail: ivzhangxiaoyan@163.com

\section{References}

[1] HUANG Chong-qi. The Application and Development of Aluminum and Aluminum Alloy for Electrical Purposes in Cable Field, Electric Wire \& Cable, 2013(2):4-9.

[2] CHEN Di, LI Chengdong, ZHAO Xiaodong. Research and Application of Aluminum Alloy in the Field of Power Transmission. Materials Review, 2013, 27(8): 145-148.

[3] FU Gao sheng, SUN Feng shan, REN Li ying, et al. The deteriorate behavior of rare earth on impurities in the industrial pure aluminum. Journal of The Chinese Rare Earth Society, 2001, 19(2): 133-137.

[4] YANG Gang, HE Zheng-fu, ZHANG Hong-yao, et al. Research on High Conductivity Al-RE-B Electrical Pole. Light Alloy Fabrication Technology, 2005, 33(7): 38-40.

[5] CHEN De-bin,XU Fu-shun,WANG Rong-li, et al. Effects of impurity elements on conductivity of the electric circular aluminum rod. Light Alloy Fabrication Technology, 2009, 37(6): 33-36.

[6] ZHONG Zhi-guo,ZUO Xiu-rong,WENG Yong-gang, et al. The application situation and the study development of the wrought aluminium alloy's homogenization. Light Alloy Fabrication Technology, 2006,34(1):10-13.

[7] LÜ Xin-yu, GUO Er-jun, Paul ROMETSCH, et al.Effect of one-step and two-step homogenization treatments on distribution of A13Zr dispersoids in commercial AA7150 aluminium alloy[J].Trans. Nonferrous Met. Soc. China 22(2012) 2645-2651 
[8] LUO J, QIU K, Wang J, et al. Microstructure and mechanical properties of Mg-7Zn-3Al alloy with Nd and Y additions [J]. Journal of Rare Earths, 2012, 5: 486-491.

[9] NIE Bo, YIN Zhi-min, ZHU Da-peng, et al.Effect of homogenization treatment on microstructure and properties of Al-Mg-Mn-Sc-Zr alloy[J].J. Cent. South Univ. Technol. 2007, 14(4):452-455.

[10] Fu G, Sun F, Ren L, et a1. Modification behavior of trace rare earth on impurity phases in commercial purity aluminum [J]. Journal of Rare Earths, 2002, 20(1): 61-66.

[11] HUANG Xin;ZHANG Xiao-yan;GAO Hong-xuan, et al. Effect of rolling deformations on properties of the electrical wire of rare earth aluminum. Light Alloy Fabrication Technology, 2014(4): 58-61.

[12] GAO Hong-xuan;ZHANG Xiao-yan;HUANG Xin, et al. The effect of Zr, Cu elements and rare earth $\mathrm{Ce}$ on microstructure and property of the electrical round rod. Journal of Functional Materials, 2015,46(3):3073-3076. 